\title{
Hava Kirlilik Modellerinde Kullanılacak Emisyon Envanteri Oluşturulması için Yaklaşımlar ve İstanbul Hava Kirliliği Dağılımı Örneği
}

\author{
Hüseyin TOROS*1, Serdar BAĞIŞ²

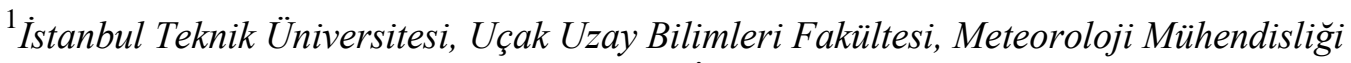 \\ Bölümü, Ístanbul

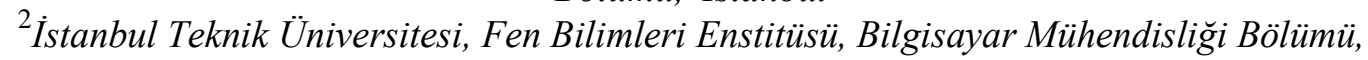 \\ Istanbul
}

Geliş tarihi: 11.02.2017～Kabul tarihi: 31.05 .2017

$\ddot{\mathbf{O} z}$

Sanayileşme ve şehirleşme hava kirliliği sorunlarına yol açmaktadır. İnsan sağlı̆̆ ve ekosistem için en ciddi tehditlerden biri nüfusun artması dolayısıyla üretimin artması ile hava kalitesinin bozulmasıdır. Bu döngü, sanayileşme ve şehirleşme yoğunluğunun yüksek olduğu alanlarda daha yoğunlaşmaktadır. Doğrudan ölçüm ile mekânsal hava kalitesinin belirlenmesi zor ve pahalıdır, bu yüzden alternatif yöntemler kullanılır, araştırılır ve geliştirilir. Bir yerin hava kalitesinin iyileştirilmesi öncelikle emisyon kaynaklarının ve miktarlarının belirlenmesi, daha sonra kirleticilerin dağılımının araştırılması, sayısal modeller vasıtasıyla dağııılması ve son olarak alınacak politikaların belirlenmesiyle yapılabilir. Emisyon envanteri hava kirliliği modellemesinde çok önemli bir adımdır ve karmaşık bir süreçtir. Şehirlerde ve şehirler arasında araç emisyonu önemli bir hava kirliliği kaynağıdır ve mekânsal emisyon dağılımını belirlemek için kullanılabilir. Yol yoğunluğu insan etkinliğinin ve şehirleşmenin dolaylı bir göstergesi olabilir, dolayısıyla insan kaynaklı hava kirliliği motorlu araçların yoğunluğu, sayısı ve türü ile dolaylı olarak nitelendirilebilir. Bu çalışma, yol haritalarıyla diğer verilerin kullanılarak emisyon envanterinin oluşturulmasına bir örnektir. Üretilen verilerin yeni nesil hava kirliliği modellerinde kullanılması, modelin başarımının arttırılmasına katkı sağlayacaktır. Çalışma sonuçları hava kalitesinin dolaylı olarak insan ve diğer canlı yaşamının iyileştirilmesi üzerine olumlu etki yapacağı düşünülmektedir.

Anahtar Kelimeler: Hava kirliliği modellemesi, Emisyon envanteri, Coğrafi bilgi sistemi, WRF-CHEM

\section{Approaches to Establish Emission Inventory for use in Air Pollution Models and A Case Study of Istanbul Air Pollution Distribution}

\begin{abstract}
Industrialization and urbanization are leading to air pollution problems. One of the most serious threats to human health and ecosystem is the degradation of air quality by man due to his necessity, the increasing
\end{abstract}

*Sorumlu yazar (Corresponding author): Hüseyin TOROS, toros@itu.edu.tr 
effect of human activity like changing landscapes, growth of cities, building of roads, and surface mining. This cycle is more intense in on areas with high industrialization and urbanization densities. Determination of spatial air quality by direct measurement is a difficult and expensive issue so alternatives methods are used, researched and developed. Air quality improvement of a place can be done firstly by determining the emission sources and quantities, then by distributing the pollutants using numerical models and finally by determining the policies to be taken. Emission inventory is a very important step in air pollution modelling and is a complex process. Vehicle emission inside and between urban areas is a major source of air pollution and it can be used to determine spatial emission distribution. Road density may be an indirect indicator of human activity and urbanization, thus human induced air pollution can be indirectly quantified by road density and by the number and type of vehicles. This study is an example of creation of emission inventory using road maps with other data. The use of generated data in the new generation air pollution models will contribute to the improvement of the performance of models. The study results are thought to have a positive impact on air quality and indirectly life satisfaction.

Keywords: Air pollution modelling, Emission inventory, GIS, WRF-CHEM

\section{GÍRİS}

Günümüzde, sanayileşme ve şehirleşmenin bir sonucu olarak ortaya çıkan hava kirliliği, soluduğumuz, kokladığımı, görünen veya görülmeyen fiziksel, biyolojik veya kimyasal olarak her gün büyüyen bir çevre sorunudur. $\mathrm{Bu}$ sorun, atmosferdeki hava bileşiklerinin değişmesi, küresel iklim değişimi, asit yağışları, ozon tabakasının seyrelmesi, yaban hayatı ve insanlar üzerindeki olumsuz etkiler oluşturarak ekosisteme zarar vermektedir. Atmosfere salınan yabancı maddelerin basınç, sıcaklık, rüzgâr, nem, yağış ve güneş radyasyonu gibi meteorolojik faktörlere, konum ve topoğrafik yapıya bağlı olarak etkileri artabilmektedir. Atmosferik bileşenleri dikkate almadan, konut ve sanayi alanlarının, bina yerleşimlerinin plansız yapılandırılması, yeşil alanların yetersizliği, sanayide hava kalitesi süzgeçlerinin yetersizliği ve yakıt kalitesizliği, şehirlerin hava kirliliğini büyük ölçüde etkilemektedir. Toros ve arkadaşları [1] tarafından sürdürülebilir bir hayat için Türkiye'deki büyük şehirlere ait hava kirliliği ve kirlilik seviyeleri araştırılmıştır. Çalışmada, doğal gaz kullanımının yaygınlaştırılması gibi son yıllardaki önemli gelişmelerin hava kalitesine olumlu etki yaptığ bildirilmiştir. Bununla birlikte meteorolojik şartlara bağlı olarak bilhassa büyükşsehirlerde zaman zaman ciddi problemler oluşturabileceği üzerine durulmuştur.
Hava kirliliği nedeniyle yerel, bölgesel ve küresel düzeyde sorunlar gözlenmektedir. İklimde oluşturduğu olumsuz etkiler başta olmak üzere geleceğimizi ciddi bir şekilde tehdit etmektedir. Hava kirliliğinin insan sağlı̆̆ı ve diğer canlılar üzerinde olumsuz etkileri bulunmaktadır. Hava kirliliğinin insanlar üzerindeki başlıca olumsuz etkileri, solunum, sinir sistemi, damar ve kalp problemleridir. Hava kirliliği değerlerinin yüksek olduğu alanlarda kirlilik, dolaylı olarak insan ölümlerine sebep olmaktadır. Dünya Sağlık Örgütü tarafından her sene 800.000 ‘den fazla ölümün çok küçük boyutta asılı partiküler madde (PM) kirliliği sonucu nefes darlığ ile meydana geldiğini tahmin edilmektedir. Bu çalışmaya göre partiküler madde kirliliği ölüm nedenleri arasında dünyada 13 . sirada gelmektedir [2-4]. Çapraz ve arkadaşları [5] yaptıkları çalışmaya göre İstanbul'da yaşanan hava kirliliğinin, solunum sistemi hastalıklarına bağlı ölümler, kalp-damar hastalıklarına bağlı ölümler ve kaza dişı tüm hastalıklar nedeniyle meydana gelen ölümler üzerinde anlamlı bir etkisinin olduğu sonucu ortaya çıkmıştır. Hava kirliliğinin yüksek olduğu alanlarda astımlı insanların sayısında bir artış vardır. İnsan faaliyetleri sonucu atmosfere salınan zararlı gaz, toz veya sıv1 maddeler soluduğumuz havada çeşitli reaksiyonlara girmektedirler. Özellikle gelişmekte olan ülke şehirlerinde hava kirliliği daha fazla artmaktadır. $\mathrm{Bu}$ ülkelerin şehirlerindeki hava 
kirliliğinin \% 90'ından fazlası, düşük yakıt kalitesi ile birlikte eski araçların yüksek sayıda olması sebebiyle ortaya çıkan araç emisyonlarından kaynaklanmaktadır. Büyük şehirlerdeki artan nüfus yoğunluğu, ekonomik, demografik, sosyal politik ve ekolojik süreçlere bağlı olarak çevrenin bozulmasıyla, yaşayanlar için sağlık riski oluşturmaktadır. Şehirlerdeki hayat memnuniyetini arttırmak için şehir planlamasının yeni vizyonları ve yenilikçi yönetim araçlarını benimsemesi kaçınılmazdır [6-7]. Tüm yapılanmalarda merkezde insan ve onu çevreleyen atmosferin göz önünde bulundurulması sosyo-ekonomik katkılar sağlayacaktır.

Değişik kaynaklardan atmosfere salınan kirleticiler mekansal ve zamansal olarak kimyasal /fotokimyasal yöntemlerle değişime uğramaktadır [7]. Kirleticiler atmosferde rüzgâr, bağıl nem, sıcaklık, sıcaklığın yükseklikle değişimi, basınç, yağış gibi meteorolojik değişkenlere bağlı olarak hareket ederler [8]. Bir yerin hava kalitesinin belirlenebilmesinde hava kirliliği ölçümleri pahalı olduğu için sayısal modeller yardımıyla kaynağından çıkan kirleticiler tahmin edilmektedir. Hava kirliliği, modelleme, emisyon envanteri çalışmaları dünyanın birçok ülkesinde farklı yaklaşımlar ve modeller ile devam etmektedir [915]. Ercelebi ve Toros [16] hava kirliliğinin belirli bir değeri aşması durumunda olumsuz etkisinin de çok fazla olması, dolayısıyla hava kirliliği tahmininin önemli olduğunu vurgulamışlardır. Hava kalitesi verisinin analiz edilerek belirli bir ihtimalle gelecekteki aşırı konsantrasyonları tahmin etmenin mümkün olabileceği üzerinde durmuşlardır.

Hava kirliliği emisyon kaynakları insan faaliyetine göre değişir. Genel olarak nüfus ve üretim artışı ile salınan hava kirliliği arasında oldukça yüksek bir ilişki vardır. Hoek ve arkadaşları [17] yaptıkları çalışmada trafik, nüfus yoğunluğu, arazi kullanımı, topografya ve iklimin hava kalitesini etkileyen önemli faktörler olduğunu bildirmişlerdir. Türkiye'de birçok model çalışması bulunmaktadır. Kimya ile birleştirilmiş hava araştırma ve tahmin modeli (Research and Forecasting model coupled with Chemistry, WRF-Chem) TÜBİTAK 111 Y319 numaralı projede çalıştırılmıştır [18]. Çalışmada model için emisyon envanteri yetersizliğinden bahsedilmiştir.

Bu çalışmada İstanbul ve çevresinde yer alan hava kalitesi istasyonlarından elde edilen 2013-2016 dönemi günlük kirlilik ölçüm verileri kullanılmıştır. Ayrıca modelleme çalışmalarına düşük maliyetli olarak emisyon envanteri oluşturma yaklaşımları sunulmuştur. Yüzey kullanım arazi verisi ile birlikte kullanılacak yol bilgisiyle emisyon envanterine yaklaşımlar verilmiştir.

\section{MATERYAL VE METOT}

\subsection{Materyal}

Bu çalışmada Çevre ve Şehircilik Bakanlığı ile İstanbul Büyükşehir Belediyesi hava kalitesi istasyonlarında ölçülen saatlik çapı $10 \mu \mathrm{m}$ 'den küçük ince partiküller $\left(\mathrm{PM}_{10}\right)$, kükürt dioksit $\left(\mathrm{SO}_{2}\right)$, azot dioksit $\left(\mathrm{NO}_{2}\right)$, karbon monoksit (CO) ve ozon $\left(\mathrm{O}_{3}\right)$ verileri kullanılmıştır. Veriler Mart 2013 ile Eylül 2016 dönemini içermektedir. Verilerin yıllık ortalama değerleri kullanılarak QGIS yazılımı ve Kriging yöntemi ile eşdeğer dağılım haritaları oluşturulmuştur. Çalışma alanı İstanbul ve Bursa'yı içine alacak şekilde $40.0^{\circ}-41.5^{\circ} \mathrm{K}$ enlemleri ile $27.5^{\circ}-30.5^{\circ} \mathrm{D}$ boylamları seçilmiştir (Şekil 1).

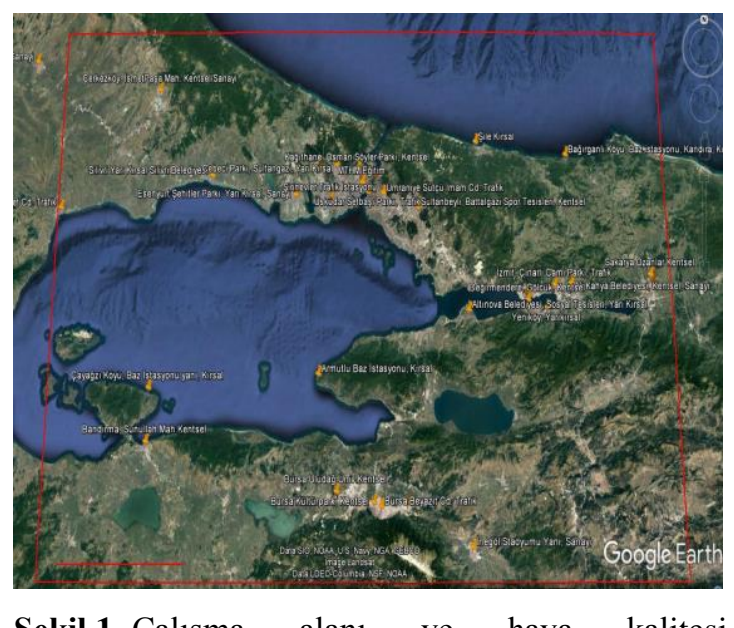
istasyonlarının konumları 
Çalışmada nüfus yoğunluğu, sanayi alanları, yerleşim yerleri ve isıtma tipi verileri, yakıt tüketimi ve motorlu taşıt istatistikleri emisyon envanteri oluşturulması için Avrupa Çevre Ajansı tarafından sürdürülen CORINE projesinden ürünlerinden faydalanılması sistematik yaklaşım açısından büyük kolaylıklar sağlayacaktır. CORINE su, toprak, arazi örtüsü, kıyı erozyonu, biyotoplar vs. konularında Avrupa Birliği için bilgi toplamayı amaçlayan bir programdır. Emisyon envanteri oluşturulmasında faydalanılabilecek bir diğer açık kaynak yol ve yerleşim bilgilerini sunan OpenStreetMap projesidir. Coğrafi olarak kirletici emisyon verileri OpenStreetMap'in yüksek çözünürlüklü yol haritasından yararlanılarak dağıtılmıştır. $\mathrm{Bu}$ haritalar diğer parametreler yanında yol ve yol türü hakkında doğru ve güncel verileri içermektedir (https://www.openstreetmap. org/).

\subsection{Metot}

Öncelikle, coğrafi bilgi sistemleri (CBS) sayesinde arazi kullanım bilgilerinden emisyon envanteri oluşturulma tekniği üzerinde durulmuştur. Bunun için geliştirilen bir yöntem ile sanayi, 1sınma ve ulaşım kaynaklarından elde edilen veriler ayrı tabakalar halinde oluşturulmuştur. Daha sonra tüm bu katmanlar tek bir emisyon tabakası haline getirilip, modele girdi oluşturulabilecek ç̧̈zünürlükte sayısallaştırılarak kullanıma sunulmuştur.

Kriging yöntemi, alansal kestirim için kullanılan geoistatistik bir yöntemdir. Ölçüm yapılan noktaların konumları ve elde edilen veriler arası korelasyon değerleri beraberinde kullanarak yansız ve en kü̧̧ük varyanslı tahmin yapabilmektedir. Farklı Kriging yöntemlerinden Simple Kriging, Ordinary Kriging, Universal Kriging, Cokriging gibi yöntemler en fazla kullanılanlardır. Yaptı̆̆ı̆ız çalışmada sadece Ordinary kriging kullanılmıştır. Enterpole edilecek noktalardaki değerlerden variogram hesaplanmıştır. Tahmin edilecek değerlerin durağan ve sabit ortalamalı olduğu varsayılmıştır. Ağırlıklar, IDW (inverse distance weighting) gibi mesafeye dayalı bir tahmin modelinde değil de, variograma dayalı olarak belirlenmiştir [19-20].

Şaylan ve arkadaşları [21] yaptıkları çalışmada, hava kirliliğinin uzun mesafe taşınımla gelen kirletici kaynaklarının tespitinde, geri yönde yörünge analiz tekniklerinin önemini vurgulamışlardır. Bölgeye başka yerlerden gelen kirlilik taşınımlarının etkisini analiz etmek için NOAA ve Avustralya meteoroloji bürosu ortaklaşa çalışması ile geliştirilen HYSPLIT (HYbrid Single-Particle Lagrangian Integrated Trajectory) modeli kullanılmıştır. Bu çalışmada GDAS küresel meteorolojik veriler kullanılmıştır. GDAS altık olarak HYSPLIT modelinde yaygın olarak kullanılmaktadır [22].

Yeni nesil ve çevrim içi bütünleşik olarak çalışan WRF-Chem modeli, WRF atmosferik sayısal modelinin atmosferik kimya modeli ile birleştirilmiş halidir. Model, aeresollerin ve diğer gazların emisyonlarını, taşınımlarını, karışmalarını ve kimyasal dönüşümlerini meteorolojik parametrelerle eş zamanlı olarak işlemektedir.

\section{BULGULAR}

İstanbul ve civarında 2013-2016 döneminde ölçümü yapılan kirliliğin zamansal ve mekânsal olarak farklılıklar gösterdiği görülmektedir. Verilerin mekânsal dağılımı için $\mathrm{PM}_{10}, \mathrm{SO}_{2}, \mathrm{NO}_{2}$, $\mathrm{CO}$ ve $\mathrm{O}_{3}$ kirleticilerinin çalışma sahası üzerindeki yıllık ortalama dağglımı Kriging istatistiki dağılım yöntemi ile elde edilmiş̧ir.

Türkiye'nin 2016 y1lı itibariyle kabul ettiğgi insan sağlığı ve ekosistemin korunması için hava kalitesi yıllık ortalama sınır değeri $\mathrm{PM}_{10}$ için $52 \mu \mathrm{g} / \mathrm{m}^{33}$ tür. İncelenen istasyonlardan Göztepe, Esenyurt, İnegöl, Tekirdağ merkez, Keşan, Bursa Beyazıt Cad., Selimiye, Çan, Kağıthane, Bursa Kestel, Çatladıkapı, Aksaray, Sakarya merkez, İzmit, 
Yenibosna, Ümraniye, Avcılar, Bilecik Bozüyük, Başakşehir, Şirinevler, Esenler, Kartal, Alibeyköy, Ümraniye, Mecidiyeköy, Kadıköy, Kocaeli
Körfez, Kocaeli Alikahya'da y1llık ortalama $\mathrm{PM}_{10}$ değerleri, sınır değeri aşmıştır (Şekil 2).

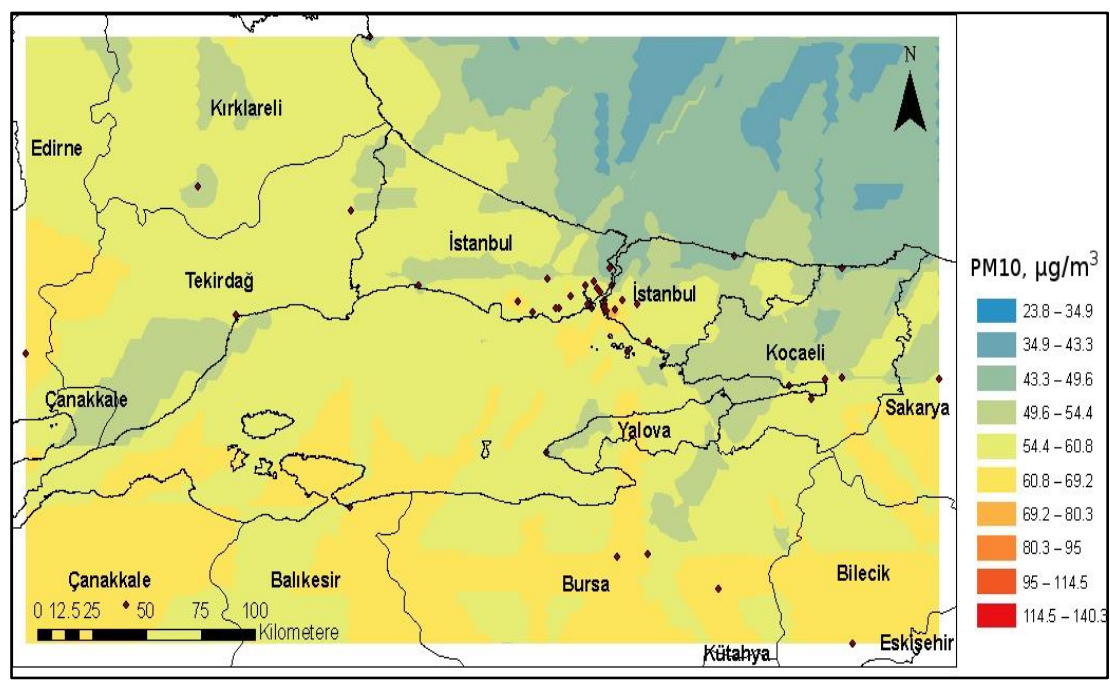

Şekil 2. $\mathrm{PM}_{10}$ yıllık ortalama dağ 1 lımları

Türkiye'nin 2016 yılı itibariyle kabul ettiği insan sağlığı ve ekosistemin korunması için hava kalitesi yıllık sınır değeri $\mathrm{SO}_{2}$ için $20 \mu \mathrm{g} / \mathrm{m}^{3}$ 'tür. Yıllık ortalama değerler incelendiğinde Keşan ve Çan başta olmak üzere, Tekirdağ merkez, Avcılar, Bursa Kestel, Lüleburgaz, İnegöl, Kocaeli Körfez istasyonlarında yıllık sınır değer aşılmıştır (Şekil $3)$.

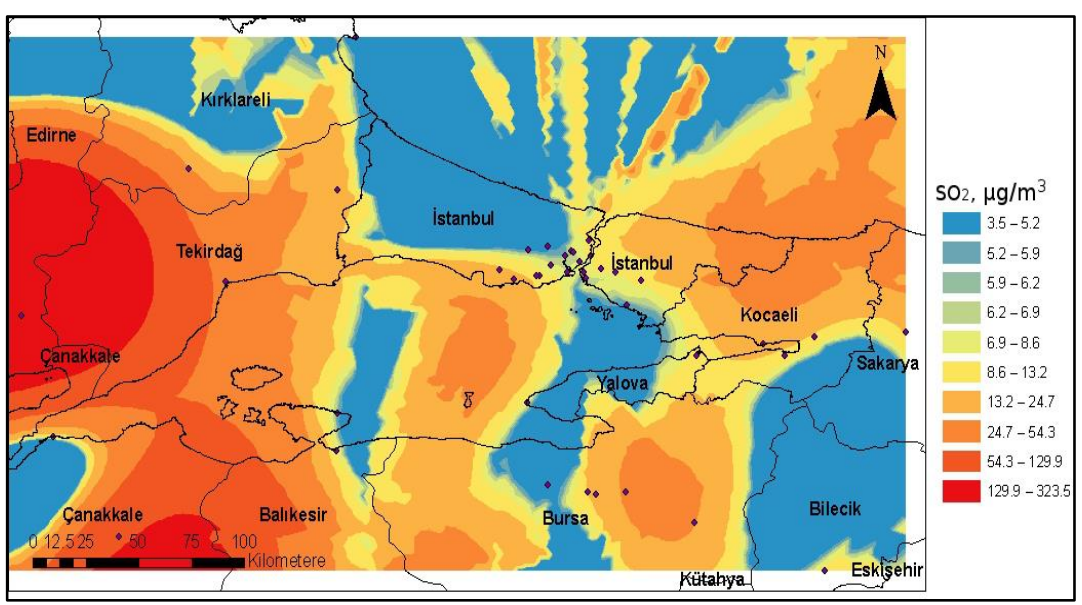

Şekil 3. $\mathrm{SO}_{2}$ yıllık ortama değerlerinin dağılımları

Türkiye'nin 2016 y1lı itibariyle kabul ettiği insan sağlığı ve ekosistemin korunması için hava kalitesi yıllık sınır değeri $\mathrm{NO}_{2}$ için $52 \mu \mathrm{g} / \mathrm{m}^{3}$ 'tür. Yıllık ortalama $\mathrm{NO}_{2}$ değerleri incelendiğinde Beşiktaş,
Mecidiyeköy, Ümraniye, Aksaray, Bursa Beyazit Cad., Çatladıkapı, Esenler, Kadıköy, Şirinevler, Ümraniye, İzmit, Üsküdar, istasyonlarında yıllık sınır değer aşılmıştır (Şekil 4). 

Dă̆ılımı Örneği

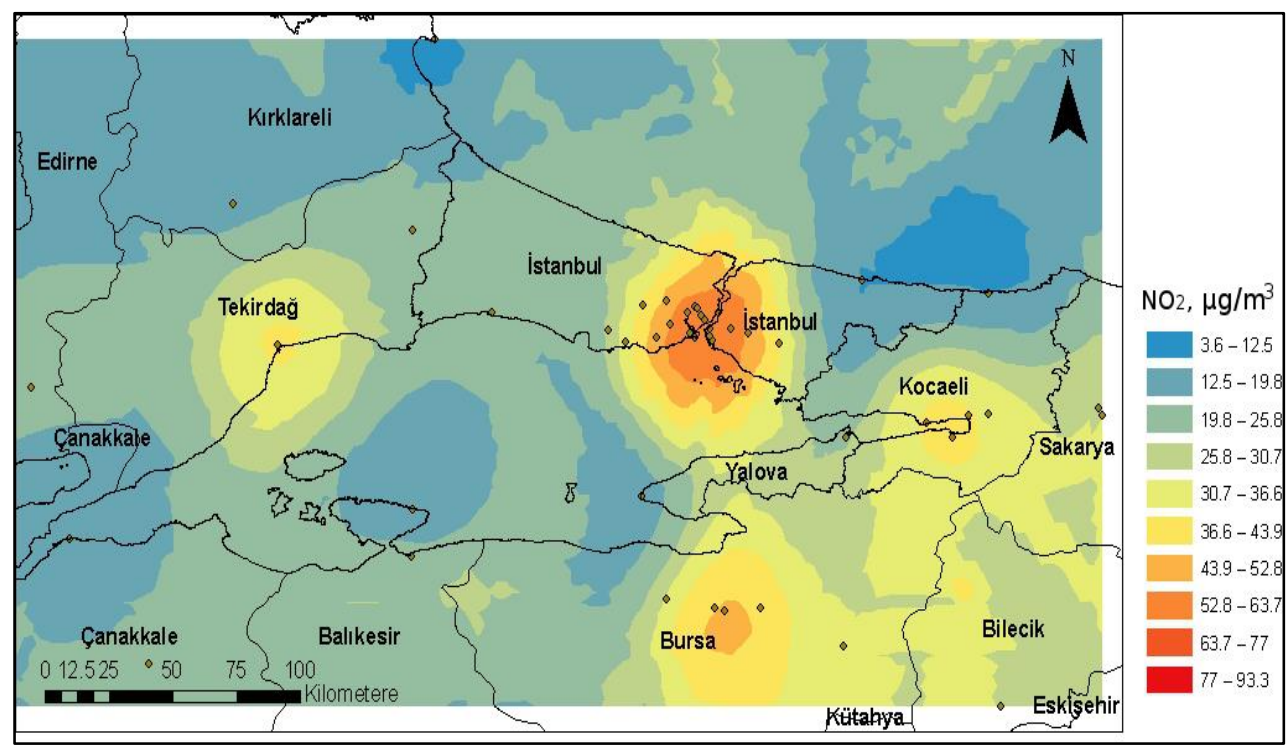

Şekil 4. $\mathrm{NO}_{2}$ yıllık ortalama değerlerinin dağılımları

Şehir alanlarında hava kirliliğinin neden olduğu ana sorunlardan biri fotokimyasal oksidanlardır. Bunların arasında ozon ve azot dioksit özellikle insan sağlığı üzerindeki olumsuz etkilerinden dolayı önemlidir [23-24]. Yere yakın seviyede ozon oluşumu güneş radyasyonunun yoğunluğuna, azot oksitler ve uçucu organik bileşiklerin yoğunluğuna ve bunlar arasındaki orana bağlıdır [25]. $\mathrm{NO}_{2}$ dağılımı (Şekil 4) ile $\mathrm{O}_{3}$ dağılımı (Şekil 5) karşılaştırıldığında, atmosfer meydana gelen, $\mathrm{O}_{3}$ $+\mathrm{NO} \rightarrow \mathrm{NO}_{2}+\mathrm{O}_{2}$ şeklindeki dönüşüm sonucu şehir içerisindeki ozonun azaldığı görülmektedir.

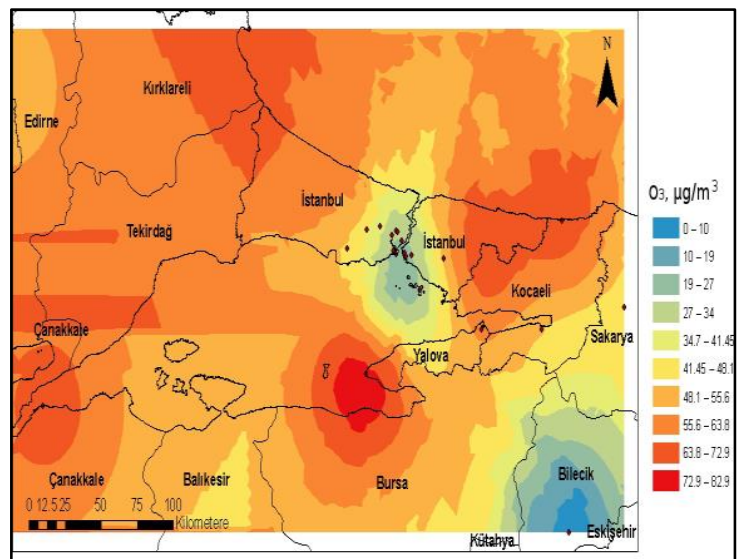

Şekil 5. $\mathrm{O}_{3}$ yıllık ortalama değerlerinin dağılımları
Y1llık ortalama karbon monoksit değerleri çalışma sahası doğusunda daha yüksek olduğu görülmektedir. CO en yüksek Selimiye, Kâğıthane, Bursa Beyazıt Cad.'de ölçülmüştür (Şekil 6).

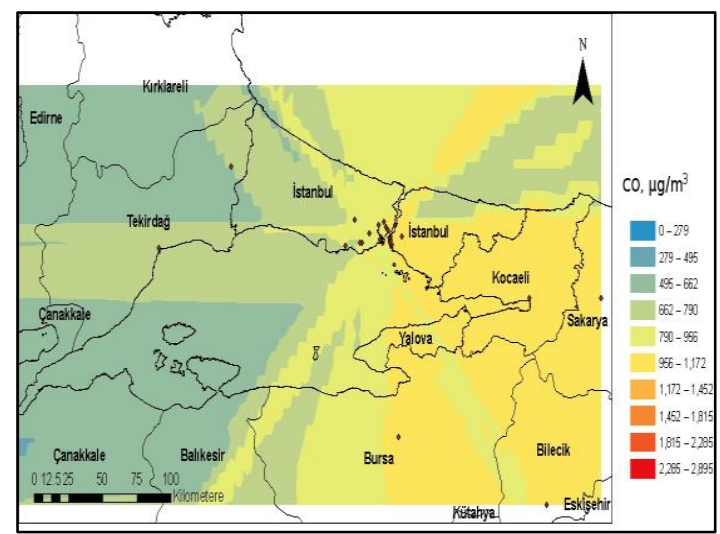

Şekil 6. CO yıllık ortalama değerlerinin dağılımları

$\mathrm{PM}_{10}, \mathrm{SO}_{2}, \mathrm{NO}_{2}, \mathrm{CO}$ ve $\mathrm{O}_{3}$ kirleticilerinin sonbahar, kış, ilkbahar ve yaz mevsimleri için ortalama değerleri Çizelge 1'de verilmiştir. Mevsimlere göre $\mathrm{PM}_{10}$ verileri en düşük olarak sonbahar, kış, ilkbahar ve yaz mevsimlerinin hepsinde Kırklareli Limanköy istasyonunda ölçülmüştür. 
Çizelge 1. İstasyonların enlemi (Enl), boylamı (Boy) ile Sonbahar (SB), Kış (KŞ, İlkbahar (İB), Yaz (YZ) ve yılllk ortalama (Ort) kirletici değerleri, $\left(\mu \mathrm{g} / \mathrm{m}^{3}\right)$

\begin{tabular}{|c|c|c|c|c|c|c|c|c|c|c|c|c|c|c|c|c|c|c|c|c|c|c|c|c|c|}
\hline \multicolumn{3}{|c|}{ İstasyon Bilgileri } & \multicolumn{5}{|c|}{$\mathbf{P M}_{10}$} & \multicolumn{5}{|c|}{$\mathrm{SO}_{2}$} & \multicolumn{4}{|c|}{$\mathrm{NO}_{2}$} & \multicolumn{5}{|c|}{$\mathrm{CO}$} & \multicolumn{4}{|c|}{$\mathbf{O}_{3}$} \\
\hline İstasyon adı & Enl & Boy & SB & $\mathbf{K S S}$ & İB & $\mathbf{Y Z}$ & Ort. & SB & KŞ & İB & $\mathbf{Y Z}$ & Ort. & \begin{tabular}{|l|l} 
SB & $\mathbf{K}$ \\
\end{tabular} & \begin{tabular}{l|l|l} 
KŞ & İ \\
\end{tabular} & \begin{tabular}{l|l}
$\mathbf{B}$ & $\mathbf{Y Z}$ \\
\end{tabular} & Ort. & SB & KȘ & İB & $\mathbf{Y Z}$ & Ort. & SB 1 & KŞSi & \begin{tabular}{|l|l|l|}
$\mathbf{I B}$ & $\mathbf{Y Z}$ \\
\end{tabular} & $\begin{array}{l}\mathbf{Z} \\
\mathbf{Z}\end{array}$ \\
\hline Bandırma & 40,35 & 27,98 & 52 & 60 & 55 & 43 & 53 & 6 & 15 & 8 & 3 & 8 & 273 & \begin{tabular}{l|l|}
30 & 28 \\
\end{tabular} & \begin{tabular}{l|l|}
8 & 21 \\
\end{tabular} & 26 & & & & & & & & & \\
\hline Erdek & 40,49 & 27,98 & & & & & & 5 & 8 & 6 & 4 & 6 & \begin{tabular}{|l|l|}
9 & 1 \\
\end{tabular} & \begin{tabular}{l|l}
12 & 9 \\
\end{tabular} & \begin{tabular}{l|l}
7 & 7 \\
\end{tabular} & 10 & & & & & & & & & \\
\hline Bozüyük & 39,90 & 30,05 & 64 & 67 & 67 & 43 & 61 & 9 & 13 & 11 & 5 & 10 & $\begin{array}{lll}333 & 3 \\
\end{array}$ & \begin{tabular}{l|l|}
35 & 31 \\
\end{tabular} & \begin{tabular}{l|l|}
1 & 23 \\
\end{tabular} & 30 & & & & & & & & & \\
\hline Beyazıt Cad. & 40,19 & 29,08 & 78 & 106 & 76 & 53 & 78 & 11 & 27 & 14 & 7 & 15 & \begin{tabular}{l|l}
68 & 7 \\
\end{tabular} & \begin{tabular}{l|l}
75 & 72 \\
\end{tabular} & \begin{tabular}{l|l}
2 & 60 \\
\end{tabular} & 69 & 1512 & 2175 & 1432 & 817 & 1484 & & & & \\
\hline İ́negöl & 40,08 & 29,50 & 86 & 135 & 75 & 49 & 86 & 25 & 31 & 24 & 15 & 24 & \begin{tabular}{|l|l|}
32 & 4 \\
\end{tabular} & \begin{tabular}{l|l}
46 & 30 \\
\end{tabular} & \begin{tabular}{l|l}
0 & 20 \\
\end{tabular} & 32 & & & & & & & & & \\
\hline Kestel & 40,20 & 29,21 & 75 & 80 & 78 & 52 & 71 & 31 & 41 & 39 & 12 & 31 & \begin{tabular}{l|l}
32 & 3 \\
\end{tabular} & \begin{tabular}{l|l}
38 & 36 \\
\end{tabular} & \begin{tabular}{l|l|}
6 & 21 \\
\end{tabular} & 32 & & & & & & & & & \\
\hline Kültürpark & 40,20 & 29,05 & & & & & & 8 & 18 & 9 & 5 & 10 & \begin{tabular}{l|l}
43 & 4 \\
\end{tabular} & \begin{tabular}{l|l}
47 & 39 \\
\end{tabular} & \begin{tabular}{l|l|}
9 & 32 \\
\end{tabular} & \begin{tabular}{|l|}
40 \\
\end{tabular} & & & & & & & & & \\
\hline Uludağ Üniv. & 40,22 & 28,87 & & & & & & 5 & 8 & 6 & 4 & 6 & \begin{tabular}{l|l}
25 & 3 \\
\end{tabular} & \begin{tabular}{l|l|}
33 & 25 \\
\end{tabular} & \begin{tabular}{l|l}
5 & 16 \\
\end{tabular} & \begin{tabular}{|l|l|}
5 \\
\end{tabular} & & & & & & & & & \\
\hline Çan & 40,03 & 27,05 & 69 & 106 & 70 & 46 & 73 & 95 & 251 & 101 & 14 & 115 & 232 & \begin{tabular}{l|l}
27 & 23 \\
\end{tabular} & \begin{tabular}{l|l}
3 & 15 \\
\end{tabular} & 22 & & & & & & & & & \\
\hline Lapseki & 40,40 & 26,77 & & & & & & 7 & 9 & 9 & 6 & 8 & \begin{tabular}{|l|l|}
9 & 1 \\
\end{tabular} & \begin{tabular}{l|l}
11 & 11 \\
\end{tabular} & \begin{tabular}{l|l}
1 & 8 \\
\end{tabular} & 10 & & & & & & $66:$ & & \begin{tabular}{l|l}
75 & 95 \\
\end{tabular} & 72 \\
\hline Karaağaç & 41,66 & 26,54 & & & & & & 7 & 14 & 6 & 4 & 8 & \begin{tabular}{l|l}
12 & 1 \\
\end{tabular} & \begin{tabular}{l|l}
13 & 10 \\
\end{tabular} & \begin{tabular}{l|l}
0 & 9 \\
\end{tabular} & 11 & & & & & & 46 & & \begin{tabular}{|l|l|}
54 & 65 \\
\end{tabular} & \begin{tabular}{l|l}
5 & 50 \\
\end{tabular} \\
\hline Keşan & 40,85 & 26,64 & 79 & 121 & 77 & 50 & 82 & 285 & 737 & 7266 & 6 & 324 & \begin{tabular}{|l|l|}
22 & 3 \\
\end{tabular} & \begin{tabular}{l|l|}
35 & 23 \\
\end{tabular} & \begin{tabular}{|l|l|}
3 & 10 \\
\end{tabular} & 22 & & & & & & & & & \\
\hline Başakşehir & 41,10 & 28,79 & 57 & 63 & 71 & 48 & 60 & 5 & 9 & 7 & 3 & 6 & \begin{tabular}{l|l}
32 & 3 \\
\end{tabular} & \begin{tabular}{l|l}
39 & 39 \\
\end{tabular} & \begin{tabular}{l|l|}
9 & 21 \\
\end{tabular} & 33 & 460 & 700 & 528 & 378 & 516 & 46 & 356 & \begin{tabular}{l|l}
62 & 78 \\
\end{tabular} & $\begin{array}{l}8 \\
855 \\
\end{array}$ \\
\hline Esenyurt & 41,02 & 28,67 & 96 & 107 & 104 & 75 & 95 & 5 & 11 & 7 & 4 & 7 & \begin{tabular}{|l|l|}
39 & 3 \\
\end{tabular} & \begin{tabular}{l|l}
35 & 38 \\
\end{tabular} & \begin{tabular}{l|l|}
8 & 25 \\
\end{tabular} & 34 & & & & & & 35 & 284 & \begin{tabular}{|l|l|}
42 & 54 \\
\end{tabular} & \begin{tabular}{l|l}
4 & 40 \\
\end{tabular} \\
\hline Kâğıthane & 41,09 & 28,98 & & & & & & 4 & 10 & 7 & 4 & 6 & \begin{tabular}{l|l}
46 & 4 \\
\end{tabular} & \begin{tabular}{l|l}
49 & 52 \\
\end{tabular} & \begin{tabular}{l|l|}
2 & 33 \\
\end{tabular} & 45 & & & & & & 30 & 223 & \begin{tabular}{|l|l|}
38 & 57 \\
\end{tabular} & \begin{tabular}{l|l|}
7 & 37 \\
\end{tabular} \\
\hline Kandilli & 41,08 & 29,06 & 46 & 54 & 50 & 35 & 46 & 8 & 13 & 15 & 7 & 11 & 334 & \begin{tabular}{l|l}
43 & 55 \\
\end{tabular} & \begin{tabular}{l|l}
5 & 33 \\
\end{tabular} & 41 & 757 & 883 & 609 & 375 & 656 & & & & \\
\hline Mecidiyeköy & 41,07 & 28,99 & 53 & 61 & 60 & 45 & 55 & & & & & & 787 & \begin{tabular}{l|l}
76 & 88 \\
\end{tabular} & \begin{tabular}{l|l}
8 & 77 \\
\end{tabular} & 80 & 682 & 1061 & 827 & 579 & 787 & & & & \\
\hline Şile & 41,17 & 29,56 & 28 & 28 & 30 & 25 & 27 & & & & & & \begin{tabular}{|l|l|}
7 & 1 \\
\end{tabular} & \begin{tabular}{l|l}
11 & 7 \\
\end{tabular} & \begin{tabular}{|l|l|}
7 & 3 \\
\end{tabular} & 7 & & & & & & & & & \\
\hline Silivri & 41,07 & 28,26 & 38 & 45 & 44 & 32 & 40 & & & & & & \begin{tabular}{l|l}
25 & 3 \\
\end{tabular} & \begin{tabular}{l|l}
32 & 26 \\
\end{tabular} & \begin{tabular}{l|l}
6 & 15 \\
\end{tabular} & 24 & & & & & & & & & \\
\hline Şirinevler & 41,00 & 28,84 & 60 & 69 & 64 & 41 & 59 & 5 & 11 & 9 & 3 & 7 & \begin{tabular}{l|l}
55 & 7 \\
\end{tabular} & \begin{tabular}{l|l}
73 & 73 \\
\end{tabular} & \begin{tabular}{|l|l|}
3 & 44 \\
\end{tabular} & 61 & 757 & 1201 & 853 & 465 & 819 & & & & \\
\hline Sultanbeyli & 40,98 & 29,27 & & & & & & 5 & 11 & 6 & 3 & 6 & \begin{tabular}{l|l}
25 & 3 \\
\end{tabular} & 3328 & \begin{tabular}{l|l}
8 & 10 \\
\end{tabular} & 24 & & & & & & 52 & & $\begin{array}{lll}66 & 80 \\
\end{array}$ & \begin{tabular}{l|l}
0 & 61 \\
\end{tabular} \\
\hline Sultangazi & 41,11 & 28,87 & & & & & & 4 & 7 & 5 & 3 & 5 & \begin{tabular}{l|l}
42 & 3 \\
\end{tabular} & \begin{tabular}{l|l}
33 & 45 \\
\end{tabular} & \begin{tabular}{l|l|}
5 & 33 \\
\end{tabular} & 38 & & & & & & 32 & 254 & \begin{tabular}{|l|l|}
43 & 53 \\
\end{tabular} & \begin{tabular}{l|l}
3 & 38 \\
\end{tabular} \\
\hline Ümraniye & \begin{tabular}{|l|}
41,02 \\
\end{tabular} & 29,10 & 63 & 69 & 64 & 51 & 62 & 6 & 7 & 7 & 4 & 6 & \begin{tabular}{l|l}
80 & 7 \\
\end{tabular} & \begin{tabular}{l|l|}
70 & 84 \\
\end{tabular} & \begin{tabular}{|l|l|}
4 & 83 \\
\end{tabular} & 79 & 1115 & 1273 & 1125 & 875 & 1097 & & & & \\
\hline Üsküdar & 41,03 & 29,03 & 40 & 53 & 51 & 30 & 44 & & & & & & \begin{tabular}{l|l}
49 & 5 \\
\end{tabular} & \begin{tabular}{l|l}
56 & 63 \\
\end{tabular} & \begin{tabular}{l|l|}
3 & 45 \\
\end{tabular} & 53 & 674 & 864 & 753 & 502 & 698 & & & & \\
\hline Limanköy & 41,89 & 28,06 & 24 & 25 & 25 & 21 & 24 & 4 & 5 & 3 & 2 & 4 & \begin{tabular}{ll|}
35 \\
\end{tabular} & \begin{tabular}{l|l}
5 & 4 \\
\end{tabular} & \begin{tabular}{|l|l|}
4 & 2 \\
\end{tabular} & 4 & & & & & & 74 & 607 & \begin{tabular}{|l|l|}
78 & 87 \\
\end{tabular} & \begin{tabular}{l|l|}
7 & 74 \\
\end{tabular} \\
\hline Lüleburgaz & 41,40 & 27,35 & 41 & 55 & 40 & 31 & 42 & 19 & 55 & 26 & 5 & 26 & \begin{tabular}{l|l}
17 & 2 \\
\end{tabular} & \begin{tabular}{|l|l|}
21 & 16 \\
\end{tabular} & \begin{tabular}{l|l|}
6 & 12 \\
\end{tabular} & 16 & & & & & & & & & \\
\hline Alikahya & \begin{tabular}{|l|}
40,77 \\
\end{tabular} & 30,01 & 49 & 66 & 58 & 38 & 53 & 9 & 13 & 18 & 5 & 11 & 283 & \begin{tabular}{l|l}
37 & 33 \\
\end{tabular} & \begin{tabular}{|l|l|}
3 & 19 \\
\end{tabular} & 29 & & & & & & & & & \\
\hline Gölcük & 40,73 & 29,80 & & & & & & & & & & & & & & & & & & & & & & & \\
\hline İzmit & 40,77 & 29,94 & 61 & 89 & 64 & 37 & 63 & & & & & & \begin{tabular}{|l|l}
546 & 6 \\
\end{tabular} & \begin{tabular}{l|l}
63 & 58 \\
\end{tabular} & 842 & 54 & 1172 & 2183 & 1202 & 646 & 1301 & & & & \\
\hline Kandıra & 41,13 & 30,01 & 35 & 35 & 42 & 39 & 38 & & & & & & \begin{tabular}{l|l}
7 & 9 \\
\end{tabular} & \begin{tabular}{l|l}
9 & 6 \\
\end{tabular} & \begin{tabular}{|l|l|}
5 & 3 \\
\end{tabular} & 6 & & & & & & 71 & 617 & \begin{tabular}{|l|l|}
76 & 83 \\
\end{tabular} & \begin{tabular}{l|l}
3 & 73 \\
\end{tabular} \\
\hline Körfez & 40,75 & 29,79 & 51 & 64 & 58 & 40 & 53 & 13 & 21 & 34 & 12 & 20 & 465 & \begin{tabular}{l|l|}
55 & 44 \\
\end{tabular} & \begin{tabular}{l|l|}
4 & 29 \\
\end{tabular} & 43 & & & & & & & & & \\
\hline Yeniköy & 40,70 & 29,88 & 40 & 49 & 46 & 30 & 41 & 8 & 12 & 13 & \begin{tabular}{|l|}
4 \\
\end{tabular} & 9 & \begin{tabular}{|l|l}
30 & 4 \\
\end{tabular} & \begin{tabular}{l|l}
40 & 32 \\
\end{tabular} & \begin{tabular}{l|l}
2 & 17 \\
\end{tabular} & 30 & & & & & & 40 & 285 & \begin{tabular}{|l|l|}
52 & 69 \\
\end{tabular} & $\begin{array}{l}9 \\
9\end{array}$ \\
\hline Merkez & 40,77 & 30,41 & 65 & 88 & 64 & 38 & 64 & & & & & & \begin{tabular}{l|l}
30 & 3 \\
\end{tabular} & \begin{tabular}{l|l}
35 & 37 \\
\end{tabular} & \begin{tabular}{l|l|}
7 & 30 \\
\end{tabular} & 33 & 1210 & 1739 & 1076 & 538 & 1141 & & & & \\
\hline Ozanlar & 40,79 & 30,40 & & & & & & 10 & 30 & 13 & 3 & 14 & \begin{tabular}{l|l}
31 & 3 \\
\end{tabular} & \begin{tabular}{l|l}
38 & 32 \\
\end{tabular} & \begin{tabular}{l|l}
2 & 19 \\
\end{tabular} & 30 & & & & & & 35 & 274 & 4962 & $\begin{array}{l}2 \\
2\end{array}$ \\
\hline Çerkezköy & 41,32 & 27,98 & 43 & 56 & 51 & 32 & 45 & 14 & 31 & 24 & 6 & 19 & \begin{tabular}{l|l}
22 & 3 \\
\end{tabular} & \begin{tabular}{l|l}
31 & 27 \\
\end{tabular} & \begin{tabular}{l|l}
7 & 13 \\
\end{tabular} & 23 & 393 & 548 & 378 & 296 & 404 & & & & \\
\hline Merkez & 40,98 & 27,50 & 75 & 106 & 86 & 68 & 84 & 24 & 113 & 38 & 4 & 45 & \begin{tabular}{l|l}
43 & 4 \\
\end{tabular} & \begin{tabular}{l|l}
47 & 51 \\
\end{tabular} & \begin{tabular}{l|l}
1 & 46 \\
\end{tabular} & 47 & 1132 & 1905 & 1180 & 752 & 1242 & & & & \\
\hline Altınova & 40,70 & 29,51 & & & & & & 7 & 10 & 11 & 6 & 9 & \begin{tabular}{l|l}
19 & 3 \\
\end{tabular} & \begin{tabular}{l|l|}
35 & 25 \\
\end{tabular} & \begin{tabular}{l|l|}
5 & 12 \\
\end{tabular} & 23 & & & & & & 49 & & \begin{tabular}{|l|l|}
60 & 78 \\
\end{tabular} & \begin{tabular}{l|l}
8 & 58 \\
\end{tabular} \\
\hline Armutlu & 40,53 & 28,79 & 31 & 30 & 33 & 30 & 31 & 6 & 7 & 6 & 5 & 6 & \begin{tabular}{|l|l}
10 & 1 \\
\end{tabular} & \begin{tabular}{l|l}
15 & 10 \\
\end{tabular} & \begin{tabular}{l|l}
0 & 8 \\
\end{tabular} & 11 & & & & & & 81 & 578 & 8710 & 683 \\
\hline Aksaray & 41,02 & 28,96 & 64 & 68 & 71 & 57 & 65 & 7 & 11 & 13 & 7 & 10 & \begin{tabular}{ll|}
675 \\
\end{tabular} & \begin{tabular}{l|l}
58 & 77 \\
\end{tabular} & \begin{tabular}{l|l|}
7 & 80 \\
\end{tabular} & 70 & 842 & \begin{tabular}{|l|}
839 \\
\end{tabular} & 949 & 761 & 848 & \begin{tabular}{|l|}
9 \\
\end{tabular} & \begin{tabular}{|l|l|}
12 & 1 \\
\end{tabular} & \begin{tabular}{l|l|}
14 & 40 \\
\end{tabular} & \begin{tabular}{l|l}
0 & 19 \\
\end{tabular} \\
\hline Alibeyköy & 41,07 & 28,95 & 58 & 56 & 59 & 50 & 56 & 3 & 5 & 6 & 3 & 4 & \begin{tabular}{l|l}
46 & 6 \\
\end{tabular} & \begin{tabular}{l|l|}
64 & 62 \\
\end{tabular} & \begin{tabular}{|l|l|}
2 & 40 \\
\end{tabular} & 53 & 565 & 587 & 520 & 335 & 502 & 25 & 193 & \begin{tabular}{|l|l|}
34 & 48 \\
\end{tabular} & \begin{tabular}{l|l}
8 & 32 \\
\end{tabular} \\
\hline Esenler & 41,04 & 28,89 & 61 & 65 & 60 & 46 & 58 & 4 & 7 & 6 & 3 & 5 & 666 & \begin{tabular}{l|l}
69 & 77 \\
\end{tabular} & \begin{tabular}{l|l|}
7 & 51 \\
\end{tabular} & 66 & 484 & 666 & 600 & 312 & 516 & & & & \\
\hline Kadıköy & 40,99 & 29,03 & 55 & 64 & 57 & 41 & 54 & 7 & 12 & 10 & 5 & 8 & \begin{tabular}{|l|l}
59 & 7 \\
\end{tabular} & \begin{tabular}{l|l}
74 & 82 \\
\end{tabular} & \begin{tabular}{l|l|}
2 & 42 \\
\end{tabular} & 64 & 695 & 837 & 1379 & 904 & 954 & 16 & \begin{tabular}{|l|l|}
17 & 1 \\
\end{tabular} & \begin{tabular}{|l|l|}
19 & 23 \\
\end{tabular} & \begin{tabular}{l|l}
3 & 19 \\
\end{tabular} \\
\hline Kartal & 40,89 & 29,21 & 60 & 70 & 59 & 44 & 58 & 4 & 5 & \begin{tabular}{|l|}
7 \\
\end{tabular} & 5 & 5 & & & & & & & & & & & & & \\
\hline \begin{tabular}{|l} 
Sariyer \\
\end{tabular} & 41,13 & 29,05 & 37 & 56 & 54 & 32 & 45 & 6 & 11 & 10 & 5 & 8 & & & & & & & & & & & & & \\
\hline Ümraniye 2 & 41,01 & 29,16 & 50 & 52 & 52 & 69 & 56 & 8 & 9 & 46 & 7 & 17 & 608 & \begin{tabular}{l|l}
82 & 58 \\
\end{tabular} & \begin{tabular}{l|l}
8 & 39 \\
\end{tabular} & 60 & & & & & & & & & \\
\hline Üsküdar 2 & 41,02 & 29,03 & 39 & 47 & 45 & 31 & 40 & 4 & 5 & 9 & 5 & 6 & & & & & 537 & 552 & 450 & 288 & 457 & & & & \\
\hline Yenibosna & 41,00 & 28,83 & 59 & 75 & 63 & 51 & 62 & 6 & 7 & 8 & 5 & 6 & & & & & 763 & 859 & 937 & 643 & 801 & & & & \\
\hline Beşiktaş & 41,05 & 29,01 & 45 & 50 & 53 & 46 & 49 & 5 & 6 & 7 & 4 & 6 & \begin{tabular}{l|l}
86 & 8 \\
\end{tabular} & \begin{tabular}{l|l}
85 & 10 \\
\end{tabular} & 893 & 93 & 508 & 819 & 750 & 840 & 729 & & & 39 & $\begin{array}{l}9 \\
9\end{array}$ \\
\hline Avcilar & 40,99 & 28,73 & & & 36 & 87 & 61 & & & 42 & 21 & 31 & & \begin{tabular}{l|l}
15 \\
\end{tabular} & \begin{tabular}{l|l|}
5 & 12 \\
\end{tabular} & 13 & & & 462 & 370 & 416 & & & & \\
\hline Büyükada & 40,86 & 29,12 & 39 & 28 & 29 & 43 & 35 & & & & & & & & & & & & & & & 202 & \begin{tabular}{|l|l|}
23 & 1 \\
\end{tabular} & 1923 & 21 \\
\hline Çatladıkapı & 41,00 & 28,98 & & 75 & 66 & 69 & 70 & & & & & & 68 & 6878 & 356 & 67 & & 1534 & 1362 & 967 & 1288 & & 192 & 2732 & 26 \\
\hline Göztepe & 40,99 & 29,07 & & 297 & 72 & 52 & 140 & & & & & & & & & & & & & & & 14 & \begin{tabular}{|l|l|}
12 & 1 \\
\end{tabular} & \begin{tabular}{|l|l|}
13 & 17 \\
\end{tabular} & 14 \\
\hline Kâğıthane 2 & 41,09 & 28,98 & 33 & 98 & 86 & 74 & 73 & 27 & 10 & 3 & 9 & 12 & 3579 & $\begin{array}{l}7943 \\
\end{array}$ & \begin{tabular}{l|l}
3 & 39 \\
\end{tabular} & 49 & 3781 & 1822 & 3333 & 1477 & 2603 & & 123 & \begin{tabular}{|l|l|}
3 & 3 \\
\end{tabular} & 5 \\
\hline Selimiye & 41,00 & 29,03 & & 77 & 97 & 57 & 77 & & & & & & & \begin{tabular}{l|l}
3 & 59 \\
\end{tabular} & \begin{tabular}{l|l}
94 \\
\end{tabular} & 47 & & 2663 & 4249 & 1775 & 2896 & & 163 & 3748 & 34 \\
\hline
\end{tabular}


Sonbahar, kış, ilkbahar ve yaz mevsimleri için $\mathrm{PM}_{10}$ değerlerinin en yüksek ölçüldüğü istasyonlar sirasiyla Esenyurt, Göztepe, Esenyurt ve Avcılar'dır. Sonbahar, kış, dönemi için $\mathrm{SO}_{2}$ değerlerinin en düşük ölçüldüğü istasyonlar sırasıyla Alibeyköy, Üsküdar ve ilkbahar ve yaz için ise Kırklareli Limanköy olmuştur. $\mathrm{SO}_{2}$ en yüksek değerleri ise yaz mevsiminde Avcılar, diğer mevsimlerde Edirne Keşan'da ölçülmüştür. $\mathrm{NO}_{2}$ değerleri tüm mevsimlerde Kirklareli Limanköy'de ölçülürken, en yüksek Beşiktaş’ta ölçülmüştür. CO değerleri en düşük yazın Üsküdar'da, diğer mevsimlerde Tekirdağ Çerkezköy'de ölçülmüştür. En yüksek sonbahar mevsiminde Kâğıthane'de, diğer mevsimlerde Selimiye'de ölçülmüştür. $\mathrm{O}_{3}$ değerleri en düşük kışın Aksaray'da diğer mevsimlerde Kâğıthane'de ölçülmüştür. En yüksek, kışın Kocaeli Kandıra'da, diğer mevsimlerde Yalova Armutlu'da ölçülmüştür.

Türkiye İstatistik Kurumu (TÜIK) istatistik verilerine göre İstanbul'da kayıtlı motorlu araçlar
Çizelge 2'de verilmiştir. Mayıs 2016 sonu itibarıla trafiğe kayıtlı toplam 20.456.556 adet taşıt bulunmaktadır. Bunların \%53,2'sini otomobil, $\% 16,3$ 'ünü kamyonet, \%14,5'ini motosiklet, $\% 8,5$ 'ini traktör, \%4'ünü kamyon, \%2,2'sini minibüs, \%1,1'ini otobüs, $\% 0,2$ 'sini ise özel amaçlı taşıtlar oluşturmaktadır. Mayıs 2016 sonu itibarıyla trafiğe kayitlı 10 milyon 885 bin 629 adet otomobilden yakit olarak \%39,9'u LPG, \%32,5'i dizel, \%27,2'si benzin kullanmaktadır. Yakıt türü bilinmeyen otomobillerin oranı ise \% 0,4’ür [26]. Araç verileri Türkiye geneli araç istatistikleriyle de karşılaştırılmıştır. İstanbul ilçe nüfus istatistikleri, ilçe çapında tek biçimli (homojen) olmadığ 1 için 900mx900m referans çalışma çözünürlüğü ile dağılım yaklaşımı yapılmıştır (Şekil 7. Openstreetmap yol verileri kullanılarak hesaplanan PM10 değerleri, (kg/km2.gün)). Bu dağ1lımın gerçeğe yakın olmas1 için yol haritası yoğunluğu, bir ağırlıklandırma faktörü olarak kullanılmıştır.

Çizelge 2. İstanbul ve Türkiye motorlu araç istatistikleri, (Şubat 2016) ve nüfus bilgisi [26]

\begin{tabular}{|c|c|c|c|c|c|}
\hline Araç tipi & İstanbul & Türkiye & $\begin{array}{c}\text { İstanbul/Türkiye } \\
\text { yüzdesi }\end{array}$ & $\begin{array}{c}\text { İstanbul araç } \\
\text { tipi yüzdesi }\end{array}$ & $\begin{array}{c}\text { Türkiye araç yakıt tipi } \\
\text { dağılımı }\end{array}$ \\
\hline Otomobil & 2488215 & 10694597 & $23,3 \%$ & $68,0 \%$ & $\begin{array}{c}39,9 \% \text { LPG, } 32,5 \% \text { mazot, } \\
27,2 \% \text { benzin }\end{array}$ \\
\hline Minibüs & 84517 & 452887 & $18,7 \%$ & $2,3 \%$ & mazot \\
\hline Otobüs & 46538 & 218322 & $21,3 \%$ & $1,3 \%$ & mazot \\
\hline Kamyonet & 616342 & 3290522 & $18,7 \%$ & $16,9 \%$ & mazot \\
\hline Kamyon & 132858 & 810352 & $16,4 \%$ & $3,6 \%$ & mazot \\
\hline Motosiklet & 259953 & 2942174 & $8,8 \%$ & $7,1 \%$ & benzin \\
\hline Özel amaçlı & 6085 & 46636 & $13,0 \%$ & $0,2 \%$ & mazot \\
\hline Traktör & 22098 & 1703693 & $1,3 \%$ & $0,6 \%$ & mazot \\
\hline Toplam & 3656606 & 20159183 & $18,1 \%$ & & \\
\hline Nüfus, 2015 & 14657434 & 78741053 & $18,6 \%$ & & \\
\hline
\end{tabular}

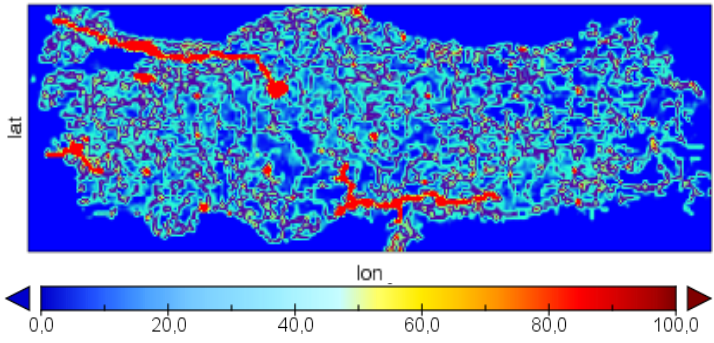

Şekil 7. Openstreetmap yol verileri kullanılarak hesaplanan $\mathrm{PM}_{10}$ değerleri, $\left(\mathrm{kg} / \mathrm{km}^{2}\right.$.gün $)$
Ekonomik olarak bir yerleşim yerindeki emisyon envanteri oluşturulması önemlidir. Bunu sağlamak için CBS ve arazi kullanım verilerinden yararlanılabilir. Böylelikle araştırılan bir bölgedeki kirletici dağılımını temsil edebilecek teknikler oluşturulabilir. CBS ve diğer kaynaklardan elde edilen sanayi, ısınma ve ulaşım verileri, geliştirilen bir yöntem ile ayrı tabakalar halinde oluşturulur. Ardından, bu katmanların tümü tek bir emisyon katmanı haline getirilir. Daha sonra elde edilen 
model girdisi istenilen çözünürlüklerde sayısallaştırılır. Böylelikle şehirlerin hava kalitesi dağılımının modellenmesi ile ilgili projelere daha emniyetli, ekonomik ve daha güvenilir bir emisyon envanteri veri tabanı sağlanabilir. Kirlilik kaynaklarından sanayi, gün içerisinde ve haftanın günlerine bağımlı olarak değişkenlik gösterebilir. Isınma, sıcaklığa bağlı iken, ulaşım da genel olarak zamana bağlıdır. Önce her kaynağa özgü emisyon katsayısı hesaplanır. Örneğin sanayi için üretilen ürün veya kullanılan yakıt, her bir yakıt için elde edilen enerji, her bir taşıt için gidilen yol göz önüne alınarak katsayı hesaplanır.

Günümüz teknolojilerinden istatistik yöntemler yardımı ile sürekli yenilenebilir, güncellenebilir ve ekonomik emisyon envanteri oluşturulması için aşağıdaki veriler değerlendirmede kullanılabilir.

1. Openstreetmap yardımıyla değişik yol tiplerine ve şehir merkezlerine yakınlığına göre farklı yüzdelerde ağırlık verilerek kirlilik dağıtılır. Ulaşım kaynakları kirletici emisyonları katmanlar halinde elde edilir.

- Karayolları;

Otoyol,

Devlet Yolu,

İl Yolu,

Köy Yolları,

Turistik Yollar,

Orman Yolları,

Şehir içi yolları için hesaplanır.

- Deniz taşımacılığı katsayıları ile deniz ulaşım emisyonları hesaplanır.

- Havaalanlarında oluşan kirlilik için günlük uçuş sayılarına ve yolcu sayılarına bağlı olarak katsayılar oluşturulur.

2. Corine verisi kullanılarak

İlçe yerleşim alanının hesaplaması

İlçe bazında nüfus yoğunluk hesaplanması

Nüfus dağılımının çıkarılması

Sanayi dağılımlarının hesaplanması yapılır.
3. Çevre ve Şehircilik Bakanlığı emisyon envanteri bilgisi ve hava kalitesi ölçüm istasyonları değerlerinden yararlanılır.

Üç farklı kaynaktan elde edilen emisyon envanteri verileri katmanlar şeklinde oluşturulur. Daha sonra atmosferik ve kimyasal dağılım modelleri ile atmosferik şartlara ve kimyasal dönüşümlere bağlı olarak dağıtılır. Ölçüm noktaları ile karşılaştırmalar yapılır. Karşılaştırma işlemlerinde yıl, ay, gün, saat bilgisi yanında meteorolojik şartlar göz ününde bulundurulur. Sanayi katmanı için çalışılan bölgedeki sanayi tesislerinin enlem ve boylamları ve o tesisten çıkan emisyonlar hesaplamalarda kullanılmıştır. Yol kirletici katmanı, ülkedeki yol haritası kullanılarak, her bir yolun niteliğine (otoyol, yan yol, mahalle, yerleşim) göre birer emisyon katsayısı ile etiketlendirilir. Etiket bilgisi ortalama bir aracın emisyon değeri ile çarpılıp, yol katmanı oluşturulur. Örneğin, burada çizgiler halindeki yol katmanı 30mx30m'lik Gauss dağılım ile etrafa yayılmıştır.

Toplanılan saha bilgileri sayesinde değişik kirlilik katmanları oluşturulmaktadır. Her bir kaynağın genel kirletici profili, sahadan konumları ile birlikte toplanıp bu katmana dâhil edilmektedir. Her katman kullanılarak, her bir kirletici için farklı bir sonuç elde edilir. Bir noktadaki kirletici, nokta halinde üretilecek sonuca doğrudan yansıtılmamalıdır. Yani herhangi bir kaynak, iki veya daha fazla pikselin kesişim sınırlarına yakın olması durumunda sonuç tek bir piksele yansımamalıdır. Tek nokta halinde değil de, nokta merkezli iki boyutlu bir Gauss dağılımı uygulandığında ve çözünürlük düşürüldüğünde, etkisi daha uygun olarak yansitılmış olur [27]. Tahmin edilen emisyon miktarları atmosferik sayısal modellerde girdi olarak kullanılmaktadır. Model sonuçları ile ölçüm sonuçları karşılaştırılarak tahmin performansı ölçülmektedir. Geri beslemeler ve özyinelemiş (içinde kendisinden bir parça bulunduran fonksiyon) döngüsü ile karar verilen çalışma alanı için en uygun model ve parametreler belirlenebilmiş olur [27]. 
Hava Kirlilik Modellerinde Kullanılacak Emisyon Envanteri Oluşturulmasına Yaklaşımlar ve İstanbul Hava Kirliliği Dă̆ılımı Örneği

İstanbul hava kirliliği ve modellenmesine örnek olarak 12-18 Ocak 2013 tarihleri arasında $\mathrm{PM}_{10}$ ölçüm değerleri incelenmiştir. 2016 yılı itibariyle Türkiye için insan sağlığı ve ekosistemin korunması için hava kalitesi günlük sınır değerleri $80 \mu \mathrm{g} / \mathrm{m} 3$ 'tür. İstasyonların çoğunluğunda 14,15 ve 16 Ocak 2013 tarihleri arasında günlük sınır değer aşılmıştır (Şekil 8). Episod için 14 Ocak tarihi için WRF-CHEM modeli küresel GFS meteorolojik veri ve RETRO/EDGAR, GOCART emisyon envanterleri kullanılarak çalıştırılmıştır. WRF-CHEM modelinin küresel veriler kullanılarak çalıştırıldığında İstanbul şehir kirliliğini yeterince temsil edilememektedir (Şekil 9). WRF-CHEM modeli sonucuna göre doğu Avrupa'dan İstanbul'a uzanan $\mathrm{PM}_{10}$ değerinin yüksek olduğu kirlilik şeridi görülmektedir (Şekil 9). İstanbul'da görülen kirliliğin uzun mesafeli taşınım ile başka bir yerden gelip gelmediği belirlemek için HYSPILT modeli GDAS meteorolojik veri ile 3 günlük geri yönde yörünge incelenmiştir. Model sonucuna göre 14 Ocak 2013 tarihindeki havanın doğu Avrupa'dan geldiği görülmektedir (Şekil 10).

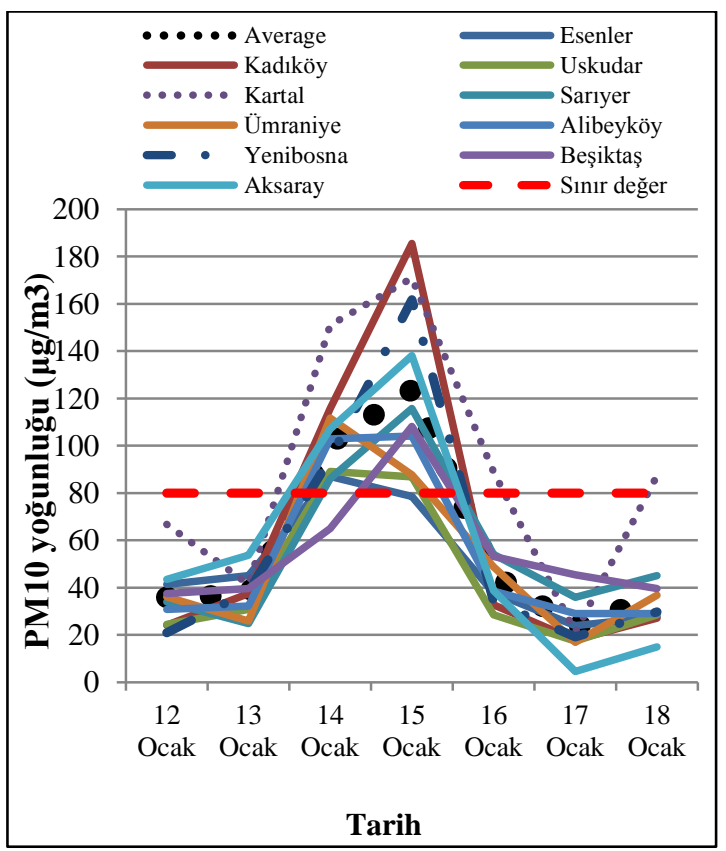

Şekil 8. 12-18 Ocak 2013 tarihleri arasında $\mathrm{PM}_{10}$ yoğunlukları
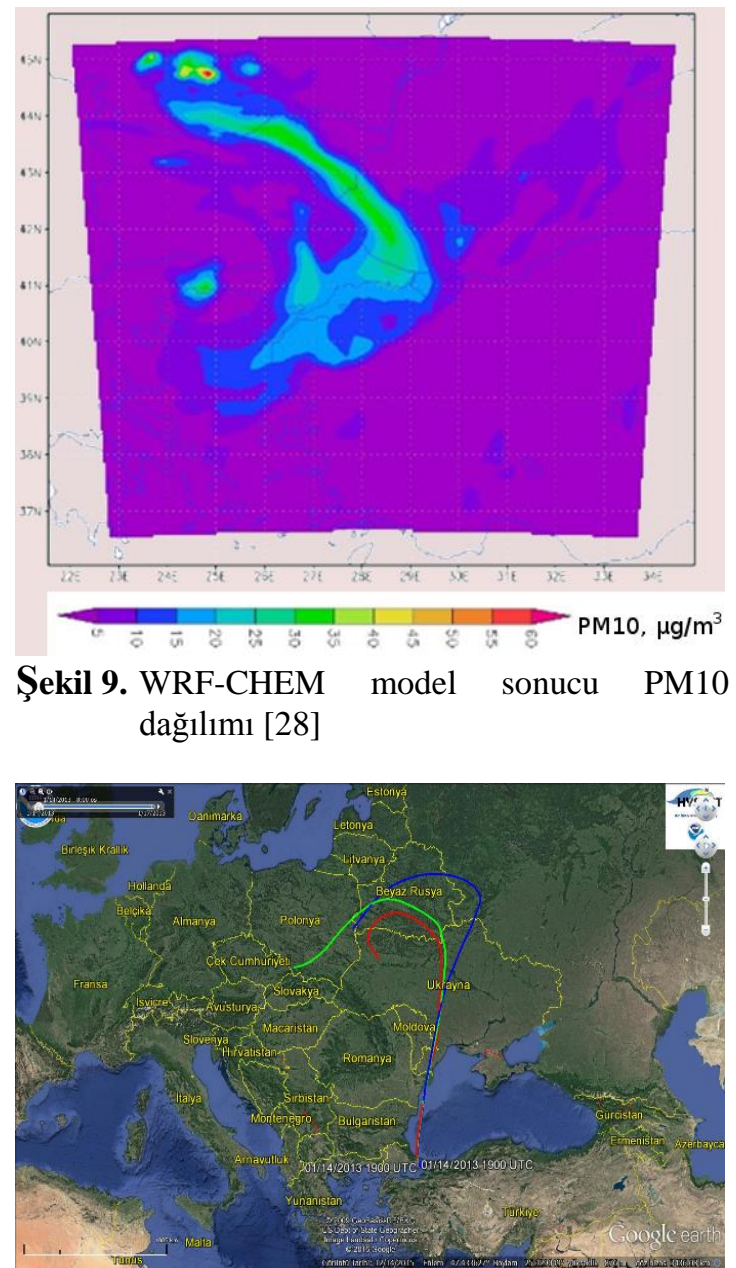

Şekil 10. 14 Ocak 2013 tarihi için İstanbul'a gelen hava taşınımının geri yönde yörünge analizi

\section{SONUÇLAR ve ÖNERÍLER}

$\mathrm{Bu}$ çalışma, yeni nesil modellerden biri olan ve dünyada kullanımı hızla artan WRF-Chem modelinin değişik emisyon envanterleri ile çalıştırılması ve elde edilen sonuçların doğruluklarının araştırılması ve daha iyi sonuçlara gidilmesine katkı sağlayacaktır. Elde edilen çıktılar, başta yerel yöneticiler olmak üzere karar vericilerin ve kamuoyunun hava kalitesi hakkında farkındalık kazanması, Türkiye hava kalitesi değerlendirilmeleri açısından çok önemli bir adım olacaktır. 
Zaman, mekan ve kaynak değişkenliği sebebiyle klasik yöntemle atmosfere salınan emisyon envanteri veri tabanının elde edilmesi zahmetli ve masraflı bir tarzdır. Bununla birlikte, dünyadaki emisyon envanterlerinin oluşturulmasının hızlı ve ekonomik olması için uzaktan algılama tekniklerinin ve bilişim çözümlerinin geliştirilerek kullanılması kolaylıklar sağlayacaktır. Yerleşim alanlarına ait yol emisyon envanterinin oluşturulmasında farklı teknikler ile coğrafi bilgi sistemlerinin araştırılması ve kullanılması, sonuçların doğruluk değerlerini arttıracaktır. Dağıtım doğruluğunu arttırmak için gelecek çalışmalarda uydu görüntülerinden hesaplanan bitki örtüsü indeksi (Normalized Difference Vegetation Index, NDVI) verileri yol haritaları ile bütünleştirilerek kullanılabilir. Bu çalışmada elde edilen tecrübe ve bilgi, sonuç olarak hızlı ve ekonomik veri tabanının geliştirilmesine aşağıdaki yollarla katkı sağlayabilir. Anlık ve uzun süreli çevre değişikliklerinin takibinde uydu verileri ve uzaktan algilama teknikleriyle elde edilecek bilgiler kullanılabilir. Hassas emisyon envanteri oluşturulmasında önemli bir etken olan trafik kirliliğini hesaplamalarında araç egzoz ölçümlerinden faydalanılabilir. Araç muayenesi sırasında aracın egzoz emisyonu ve bir önceki ölçümlerden sonra aldığı toplam yol uzunluğu vs. bilgilerin toplanılması ve erişilebilir hale getirilmesi önem arz etmektedir. Ulaşım kaynaklı emisyon katsayısını hesaplamak için yerleşim alanlarında, merkezden kenarlara doğru azalan istatistiki bir yöntem kullanılabilir.

Oluşturulan emisyon envanteri WRF-CHEM gibi yeni nesil ve çevrimiçi çalışan atmosferik ve kimyasal modellerde girdi olarak kullanılabilir. Model sonuçları ile ölçüm sonuçları karşılaştırılarak elde edilen bilgiler, yöntemde iyileştirme amaçlı geri dönüşüm bilgisi olarak kullanılabilir.

\section{KAYNAKLAR}

1. Toros, H., Erdun, H., Çapraz, Ö., Özer, B., Daylan, E.B., Öztürk, A.İ., 2013. Air Pollution and Quality Levels in Metropolitans of Turkey for Sustainable life, European Journal of Science and Technology, EJOSAT, 1, 12-18.
2. CDC, 2014. Heart Health and Air Pollution a Tool Kit, https://ephtracking.cdc.gov/docs/CDC_HeartH ealth_Final.pdf.

3. Toros, H., Geertsema, G., Cats, G., 2014. Evaluation of the HIRLAM and HARMONIE Numerical Weather Prediction Models During an Air Pollution Episode Over Greater İstanbul Area. CLEAN - Soil, Air, Water, 42(7), 863-870.

4. Özelkan, E., Karaman, M., Mostamandy, S., Uça Avc1, Z.D., Toros, H., 2015. Derivation of PM10 Levels Using OBRA on Landsat-5TM Images: A Case Study in Izmir, Turkey, Fresenius Environmental Bulletin, 24, 1585-1596.

5. Çapraz, Ö., Efe, B., Deniz, A., 2015. Study on the Association Between Air Pollution and Mortality in İstanbul, 2007-2012. Atmospheric Pollution Research, 7(1), 147-154.

6. Incecik, S., Im, U., 2012. Air Pollution in Mega Cities: A Case Study of Istanbul, Air Pollution - Monitoring, Modelling and Health, Book, Editor. Dr. Mukesh Khare, s. 3-41.

7. Toros, H., 2000. İstanbul'da Asit Yağışları, Kaynakları ve Etkileri, Doktora Tezi, 110s, İTÜ.

8. Sen, O., 1997. Inversions and Air Pollution in Istanbul, International Journal of Environment and Pollution, No. 8 (1-2), 1997, s. 158-163.

9. Tayanç, M., 2013. Türkiye'de Hava Kalitesi Modellemesi. Hava Kirliliği Araştırmaları Dergisi, 2, 112-122.

10. Deniz, A., Çelebi, M.H., İncecik, S., Toros, H., 2013. Analysis of Ozone and its Precursors at an Urbanized and Industrialized Creek Valley (Golden Horn, Istanbul, Turkey), Fresenius Env. Bul., 22(9), 2524-2532.

11. Eum, Y., Song, I., Kim, H.C., Leem, J.H., Kim, S.Y., 2015. Computation of Geographic Variables for Air Pollution Prediction Models in South Korea, Environmental Health and Toxicology, 30, 1-14.

12. Li, G., Weng, Q., 2005. Using Landsat ETM+ Imagery to Measure Population Density in Indianapolis, Indiana, USA. Photogrammetric Engineering \& Remote Sensing, 71(8), 947-958. 
13. Habermann, M., Medeiros, A.P.M., Gouveia, N., 2011. Vehicular Traffic as a Method to Evaluate Air Pollution in Large Cities, Rev. Bras. Epidemiol., 14(1), 1-11.

14. Markakis, Ki, Im, U., Unal, A., Melas, D., Yenigun, O., Incecik, S., 2012. Compilation of a GIS Based High Spatially and Temporally Resolved Emission Inventory for the Greater Istanbul area, Atmospheric Pollution Research, 3(1), 112-125.

15. Ozdemir, H., Mertoglu, B., Demir, G., Deniz, A., Toros, H., 2012. A Case Study of Particulate Matter Pollution at the Playgrounds in Istanbul using Field Measurements and Meteorological Modeling, Theoretical and Applied Climatology, 108(3-4), 553-562,

16. Ercelebi, S.G., Toros, H., 2009. Extreme Value Analysis of Istanbul Air Pollution Data, CLEAN - Soil, Air, Water, 37(2), 122-131.

17. Hoek, G., Beelen, R., De Hoogh, K., Vienneau, D., Gulliver, J., Fischer, P., Briggs, D., 2008. A Review of Land-use Regression Models to Assess Spatial Variation of Outdoor Air Pollution. Atmospheric environment, 42(33), 7561-7578.

18. Toros, H., İncecik, S., Deniz, A., Arslan, M., Dursun, Ş., Öztürk, A.İ., 2015. 111Y319. Hava Kalitesi ve Meteorolojik Modellerin Online Entegrasyonu. (COST Action ES1004 European framework for Onlıne Integrated Air Quality and Meteorology Modelling).

19. Isaaks, E.H., Srivastava, M.R., 1989. An Introduction to Applied Geostatistics, Oxford University Pres, New York.

20. Lang, C., 2006. Kriging Interpolation. http://www.nbb.cornell.edu/neurobio/land/Old StudentProjects/cs490-94to95/clang/kriging. html, (10.01.2006).

21. Şaylan, L., Toros, H., Şen, O., 2009. Back Trajectory Analysis of Precipitation Chemistry in the Urban and Forest Areas of Istanbul, Turkey, CLEAN - Soil, Air, Water, 37(2), 132-135.

22. Rolph, G.D., 2016. Real-time Environmental Applications and Display System (READY) Website (http://www.ready.noaa.gov). NOAA Air Resources Laboratory, College Park, MD.

23. Panis, I.L., Broekx, S., Liu, R., 2006. Modelling Instantaneous Traffic Emission and the Influence of Traffic Speed Limits. Science of the Total Environment, 371, 270-285.

24. WHO, 2000. Guidelines for Air Quality, World Health Organization, Geneva. p. 190.

25. Nevers, N.D. 2000. Air Pollution Control Engineering, seconded. McGraw-Hill Companies, Inc., New York, s. 571-573.

26. TÜİK, 2016. TÜİK-Haber Bülteni / Motorlu Kara Taşıtları, Şubat 2016

27. Bağış, S., Çavuş, P.C., Toros, H., 2015. CBS Yardımıyla Emisyon Envanteri Oluşturulması: Ankara Örneği, 335-347, 7. Atmosfer Bilimleri Sempozyumu, İSTANBUL, 28.04.201530.04.2015.

28. Mostamandy, S., Toros, H., 2015. A Case Study of Online Enviro-Hirlam and Wrf-Chem Model During An Air Pollution Episode in Istanbul, 1039-1049, 7. Atmosfer Bilimleri Sempozyumu, İSTANBUL, 28.04.201530.04.2015. 